\title{
Um olhar na teoria da aprendizagem de Bruner sobre o ensino de Ciências
}

\author{
A look at Bruner's learning theory on Science teaching \\ Una mirada a la teoría del aprendizaje de Bruner sobre la enseñanza de las Ciencias
}

Recebido: 29/09/2021 | Revisado: 05/10/2021 | Aceito: 13/10/2021 | Publicado: 16/10/2021

\author{
Ana Flavia Corrêa Leão \\ ORCID: https://orcid.org/0000-0002-8585-5280 \\ Universidade Federal do Pampa, Brasil \\ E-mail: analeao.aluno@unipampa.edu.br \\ Mara Elisangela Jappe Goi \\ ORCID: https://orcid.org/0000-0002-4164-4449 \\ Universidade Federal do Pampa, Brasil \\ E-mail: maragoi@unipampa.edu.br
}

\begin{abstract}
Resumo
Diversos modelos que buscam explicar o processo de aprendizagem foram sendo estruturados para que se possa entender aspectos relacionados ao ensino. Esses modelos, chamados de Teorias de Aprendizagem, servem então para mudar panoramas, pois, sabe-se que a forma com que o ensino vem sendo conduzido é ineficaz. Tendo como referência os rumos que o ensino está tomando, visto que o mesmo apresenta-se descontextualizado com a realidade e interesse dos alunos, procura-se neste artigo apresentar a Teoria de Aprendizagem estruturada por Jerome Bruner, de maneira a abordar seus fundamentos teóricos, a fim de que os mesmos possam ser empregados como referencial de apoio às atividades didáticas e que possa possibilitar que ensino alcance resultados positivos. Desta forma, espera-se contribuir na melhoria da qualidade do ensino, em especial o Ensino de Ciências em escolas brasileiras, visto que em outros países da Europa e Estados Unidos, a Teoria de Jerome Bruner já vem sendo trabalhada e divulgada promovendo um ensino voltado às particularidades cognitivas de cada indivíduo.
\end{abstract}

Palavras-chave: Fundamentos teóricos; Referencial de apoio; Atividades didáticas.

\begin{abstract}
Several models that seek to explain the learning process have been structured in order to understand aspects related to teaching. These models, called Learning Theories, then serve to change perspectives, as it is known that the way teaching has been conducted is ineffective. With reference to the directions that teaching is taking, as it is out of context with the reality and interest of students, this article seeks to present the Learning Theory structured by Jerome Bruner, in order to address its theoretical foundations, so that they can be used as a support reference for didactic activities and that can enable teaching to achieve positive results. In this way, it is expected to contribute to improving the quality of teaching, especially Science Teaching in Brazilian schools, since in other European countries and the United States, Jerome Bruner's Theory has already been worked on and disseminated, promoting a focused teaching to the cognitive particularities of each individual.
\end{abstract}

Keywords: Theoretical foundations; Support reference; Didactic activities.

\section{Resumen}

Se han estructurado varios modelos que buscan explicar el proceso de aprendizaje con el fin de comprender aspectos relacionados con la docencia. Estos modelos, llamados Teorías del Aprendizaje, sirven para cambiar perspectivas, ya que se sabe que la forma en que se ha llevado a cabo la enseñanza es ineficaz. En cuanto a los rumbos que está tomando la enseñanza, por estar fuera de contexto con la realidad e interés de los estudiantes, este artículo busca presentar la Teoría del Aprendizaje estructurada por Jerome Bruner, con el fin de abordar sus fundamentos teóricos, para que puedan ser. utilizado como referencia para apoyar las actividades didácticas y que puede permitir que la enseñanza logre resultados positivos. De esta manera, se espera contribuir a mejorar la calidad de la enseñanza, especialmente la Enseñanza de las Ciencias en las escuelas brasileñas, ya que en otros países europeos y en Estados Unidos, la Teoría de Jerome Bruner ya se ha trabajado y difundido, promoviendo una enseñanza enfocada en las particularidades cognitivas de cada individuo.

Palabras clave: Fundamentos teóricos; Referencia de soporte; Actividades didácticas.

\section{Introdução}

Durante a evolução histórica dos processos de ensino e aprendizagem várias teorias foram sendo estruturadas para entender alguns aspectos relacionados ao ensino e ao perfil comportamental do aluno durante o seu desenvolvimento do 
conhecimento. Essas teorias servem então, para mudar panoramas como o do método de ensino vertical da exposição e cobrança de conhecimentos através de provas e resultados mensuráveis, ainda presentes no ensino tradicional, além de ineficazes. Na concepção de Piaget (2008), gerar a inteligência mais que vestir a memória é preparar pesquisadores e não eruditos, é um dos objetivos da educação intelectual, os quais não se aplicam no ensino tradicional.

Sendo assim, novas teorias precisam ser analisadas com a intenção de que sejam sanadas as carências do método tradicional, encontrado nos meios escolares de ensino nos dias de hoje. Para Piaget (2008, p.78), “[...] a natureza da inteligência ou do conhecimento, o papel da experiência na formação das noções e o mecanismo das transmissões sociais ou linguísticas do adulto a criança" devem influenciar na escolha do melhor método a ser utilizado no ensino, no contexto atual.

Compreendendo-se que as teorias da aprendizagem são:

[...] uma construção humana para interpretar sistematicamente a área de conhecimento que chamamos aprendizagem. Representa o ponto de vista do autor/pesquisador como intérprete de aprendizagem [...]. Tenta explicar o que é aprendizagem e porque funciona como funciona (Moreira, 1999. p.12).

Ao analisar o ambiente escolar da Educação Básica observa-se que nas úlitmas décadas ocorreram diversas mudanças estruturais de currículo, mas que as concepções de aprendizagem continuam retrógradas; mesmo que nos meios acadêmicos de formação de professores sejam abordados e sugeridas diversas teorias para aperfeiçoar os processos de ensino e de aprendizagem. Busca-se portanto, uma teoria de aprendizagem capaz de colocar o estudante como protagonista junto ao professor e que possibilite ao mesmo ser participante ativo na aquisição de seus conhecimentos.

Visando uma solução para o Ensino de Ciências determina-se Jerome Bruner como marco referencial da Psicologia de Aprendizagem, por propor uma estratégia de ensino através da Resolução de Problemas, fazendo com que o aprendiz possa experimentar a descoberta de uma relação científica entre conceitos, o que é uma das características fundamentais para o Ensino de Ciências. (Oliveira, 1973 apud Moreira, 1999).

Sendo assim, este artigo pretende-se abordar aspectos da biografia de Jerome Bruner, além das implicações de sua teoria de aprendizagem aplicada ao Ensino de Ciências, evidenciando a aprendizagem por descoberta e o currículo em espiral. Essa escolha deu-se por considerar suas concepções de como as experiências afetam a percepção e o comportamento humano, bem como a cultura e o meio em que vive. Outro fato que chama atenção para Bruner é o seu interesse em como as crianças aprendem, enfatizando a aprendizagem por descoberta, a qual induz a participação ativa do aprendiz no processo de aprendizagem. Vindo de encontro com o aprender significativamente, o que para Ausubel et al (1980) é ampliar e reconfigurar ideias já existentes na estrutura mental e com isso ser capaz de relacionar e acessar novos conteúdos.

A metodologia empregada na pesquisa foi um estudo bibliográfico, que teve por finalidade levantar as referências encontradas sobre Jerome Bruner. Segundo Cervo e Bervian (2002) essas referências podem estar em qualquer formato, ou seja, livros, sites, revistas, vídeo, enfim, tudo que possa contribuir para o objeto de estudo investigado.

\section{Jerome Seymour Bruner ${ }^{1}$}

No contexto da época, a Psicologia abrangia, em sua disciplina, o estudo das percepções, mais subjetivo e da análise, mais objetivo e comportamental. Para Silva e Gomes (2017 apud Amil, s.d.) em Harvard, os behavioristas organizaram um programa que conceituava a Psicologia como estudo dos sentidos relacionados com as energias físicas, esse programa de

\footnotetext{
${ }^{1}$ Nasceu em Nova York no dia primeiro de outubro de 1915 e faleceu em junho de 2016. Teve problemas de visão ao nascer, não podendo enxergar até os dois anos de idade, quando fez duas cirurgias de catarata recuperando a visão, mesmo que de maneira limitada. Segundo Silva \& Gomes (2017 apud AMIL, s.d.) Bruner foi aluno de escola pública, terminando o Colegial em 1933, iniciando logo em seguida Psicologia na Universidade de Duke, na Carolina do Norte, Estados Unidos. Fez mestrado em 1939 e doutorado em 1941, na Universidade de Harvard. Juntou-se ao exército na Segunda Guerra Mundial, servindo no departamento de inteligência militar, onde usou seu treinamento para analisar propaganda. No período de 1945 a 1972 fez parte do corpo docente da Universidade de Harvard.
} 
investigação denominava-se Psicofísica, ao qual Bruner se mostrou contrário. Sendo assim, Bruner uni-se com Leo Postman e implementou experimentos cujos resultados trouxeram uma nova teoria da percepção, chamada "New Look", sendo que o postulado dessa teoria, refere-se que necessidades e valores são o que determinam as percepções humanas.

Tanto Bruner como Leo Postman (1949 apud Kuhn, 1998) argumentam que observar como as pessoas interpretam o mundo, bem como reagem a estímulos é dever da Psicologia. Ainda, conforme Silva e Gomes (2017 apud Amil, s.d.) o interesse pelas percepções do homem levou Bruner a estudar as características cognitivas, que foram estimuladas a partir de debates feitos, em 1950, com Robert Oppenheimer, sobre como as ideias de um cientista pode determinar o fenômeno natural em observação.

De acordo com Silva e Gomes, (2017 apud Amil, s.d.), A Study of Thinkin [1956], artigo escrito por Bruner em colaboração com Jacqueline Goodnow e George Austen, foi relevante para a época, pois se preocupou em analisar como as pessoas organizam o pensamento em classes e categorias, concluindo que classificar as coisas envolve procedimentos e critérios.

Conforme descreve Silva e Gomes (2017 apud Amil, s.d.), em 1960, Bruner foi um dos fundadores do Centro de Estudos Cognitivos na Universidade de Harvard, tendo como um dos diretores do Centro George Miller. Ele estava focado em estudar a maneira pela qual as pessoas desenvolviam seus modelos conceituais e em saber como eles codificaram informações sobre esses modelos. Bruner e Miller pensavam que a Psicologia deveria cuidar das maneiras pelas quais os seres humanos adquirem, armazenam e trabalham com o conhecimento, isto é, tudo relacionado aos processos cognitivos. Em seu modelo, os alunos desempenham outro papel, pois são motivados a descobrir os fatos por si mesmos e a construir seu conhecimento a partir do que já sabem. Foi com base nessa ideia que Jerome Bruner desenvolveu em 1960 o aprendizado por descoberta ${ }^{2}$ ou aprendizado heurístico, uma teoria de natureza construtivista.

Em 1965, ainda conforme Silva e Gomes (2017 apud Amil, s.d.), Bruner foi presidente da Associação Americana de Psicologia (APA). A fim de verificar como uma lei define um comportamento apropriado, em meados dos anos de 1990, Bruner transferiu-se para a Faculdade de Direito da Universidade de Nova York.

\section{Implicações da Teoria de aprendizagem de Bruner}

Segundo Bruner (1973c), como a Psicologia apresenta muitas teorias abordando o ensino e desenvolvimento, uma teoria da aprendizagem deve ser estabelecida de maneira que se consiga obter mais conhecimento e que possibilite analisar sobre a necessidade da mesma. Ressalta-se que estas teorias são descritivas e não prescritivas, pois tratam das decorrências de um acontecimento, conforme destacado no exemplo a seguir:

[...] a maioria das crianças de seis anos não possui ainda a noção de reversibilidade. Uma teoria de aprendizagem, por seu lado, deveria esforçar-se para oferecer a melhor maneira de dar às crianças aquela noção. Preocupa-se, em resumo, em como algo a ensinar pode ser mais bem apreendido, isto é, em melhorar e não em descrever o ensino (Bruner, 1973a, p.48).

Essa análise, segundo Bruner (1973c), indica que as teorias podem abordar outras questões além das questões relacionadas à aprendizagem, mas também de desenvolvimento e isso não diminui a importância das teorias psicológicas para com as teorias de ensino.

Para Bruner (1973c) uma teoria de ensino deve apresentar quatro características: (1) apontar as experiências mais

\footnotetext{
${ }^{2}$ A Aprendizagem por Descoberta de Bruner difere do Modelo de Redescoberta (1950 a 1970) que adotava muitos princípios e conceitos do modelo tradicional, chamado transmissão do conhecimento e o estímulo-resposta, procurando evitar aulas expositivas, preferindo as atividades experimentais com roteiros fechados. Já a aprendizagem por Descoberta não deve ser limitada a uma memorização mecânica de informação ou de procedimentos, mas sim conduzir o educando ao desenvolvimento da sua capacidade para solucionar problemas e pensar sobre a situação que enfrenta, sendo que nas atividades experimentais não existe um roteiro, vão sendo construídas (Moreira,1999).
} 
efetivas para que ocorra a predisposição para aprendizagem; (2) especificar como estruturar os conhecimentos, para melhor ser entendido e aprendido pelo aluno; (3) indicar a sequência mais eficiente para aprender os conteúdos a serem abordados; (4) conter-se na natureza e na aplicação dos prêmios e punições no processo de ensino e aprendizagem.

Quanto à predisposição para aprender, Bruner (1973c) sinaliza que nos processos de ensino e de aprendizagem e na solução de problemas, há uma influência importante de fatores culturais, motivacionais e pessoais, visto que o processo de ensino é social, pois se estabelece nas relações obtidas entre quem ensina e quem aprende, assim, pode-se colocar em evidência a relação professor- aluno.

[...] Tratando-se de relação entre pessoas em que um possui algo que falta ao outro,há sempre,no caso,um problema de autoridade.A forma dessa relação de autoridade se reflete na natureza da aprendizagem, no grau em que o estudante desenvolve uma habilidade independente, na medida em que ele confia na capacidade própria para trabalhar sozinho, e assim por diante. As relações entre quem ensina e quem aprende repercutem sempre na aprendizagem. E desde que o processo do ensino é essencialmente social - principalmente nos seus primeiros estágios, quando abrange, no mínimo, um professor e um aluno -, é claro que uma criança que tem que ir à escola deve ter um mínimo de conhecimentos sociais para poder participar do processo de aprendizagem escolar (Bruner, 1973c, p.50).

Bruner (1973c) chama atenção para um fator importante, na predisposição para explorar alternativas, propondo que a instrução deverá facilitar e ordenar o processo de aprendizagem do estudante. Destaca que existem três fatores envolvidos no processo de exploração:(1) A ativação, sendo o que dá início ao processo; (2) A manutenção, que serve para que o processo se mantenha; (3) A direção, que evitará que ele siga por caminhos indesejados. Esses aspectos são caracterizados como exploração de alternativas e para que ocorra a mesma é necessário que exista uma certa curiosidade, gerada por grandes incertezas. Assim, trabalhar com rotinas não proporcionam ao aluno o desejo de solucionar problemas (Bruner, 1973c).

Quanto à estrutura e forma de conhecimento, Bruner (1973c) destaca que todo o tipo de conhecimento pode ser simplificado ao ponto de possuir um grau mínimo de complexidade e, desta forma, ser compreendido por qualquer aluno.

A estrutura de uma matéria apresentada pode ser caracterizada pela sua forma de representação, sua economia e a sua potência efetiva, todas elas relacionadas à habilidade do aluno no domínio dos assuntos. As formas de representação podem ser de três tipos: ativas, icônicas e simbólicas. A quantidade de informação a ser armazenada e utilizada para solucionar problemas está relacionada à economia na representação de um domínio. A ordem que a matéria é apresentada e estudada relaciona-se com a forma de representação. Já a capacidade que o aluno tem de enfrentar tarefas intelectuais refere-se a potência efetiva.

Sequências referem-se a um passo a passo sobre um assunto que quando apresentado ao aluno, além de aumentar a capacidade de compreender e transformar o assunto em estudo, contribua para sua aprendizagem, compreensão e aquisição do conhecimento (Bruner, 1973c).

Há sequências diferentes que se mostram de facilidade ou dificuldade equivalentes para os alunos, e não há uma sequência única para todos, dependendo o índice ótimo em um caso particular de todo um conjunto de fatores, como o cabedal de informações, o estágio de desenvolvimento, a natureza da matéria e as diferenças individuais. (Bruner, 1973c, p. 56).

Uma influência sobre a aprendizagem do aluno é a compreensão dos resultados, pois dependendo de seu uso, auxiliará ou não o aluno na aquisição do seu conhecimento (Bruner, 1973c).

Baseados em uma característica comum, pode-se caracterizar os estudos e a Resolução de Problemas em diferentes fases. Essa etapa, que consiste em uma verificação de hipóteses, é conhecida como ensaio erro.

[...] O conhecimento dos resultados deverá ser dado a alguém no momento exato de uma resolução de problemas, quando está comparando os resultados de sua tentativa com o critério que ele procura satisfazer. Se dado antes,não será atendido ou será apenas uma carga adicional na memória imediata. Se dado depois, poderá ser tarde demais para orientar na 
escolha de nova hipótese tentativa. Mas, para ser útil, não deverá o conhecimento dos resultados limitar-se a informar se determinada ação de uma pessoa foi bem sucedida ou não, mas também dizer se tal ação está ou não a conduzindo através de uma hierarquia de metas a atingir [...]. (Bruner, 1973c, p.57).

Assim, objetiva-se oportunizar ao aluno o domínio do conteúdo que lhe foi apresentado e que não necessite seguidamente da presença do professor, de modo que o aluno desenvolva um senso de autonomia e ao professor cabe oferecer ferramentas e ações favoráveis, colaborando com o desenvolvimento do aluno (Bruner, 1973c).

A teoria de Bruner está alicerçada na Filosofia Construtivista3. Essa, vê a teoria de Bruner como algo que permite ao aluno ir além das informações dadas, como um aluno que é capaz de atribuir significado e ser construtor de sua própria aprendizagem. Segundo Ornelas (2009, p.4):

Seguidor da Teoria Construtivista, Bruner refere que o desenvolvimento pessoal parte de processos de descoberta espelhados em situações variadas e que as informações retidas pelo aluno surgem dentro de uma estrutura cognitiva construída por si próprio, composta por esquemas e modelos mentais, que lhe permite selecionar e transformar a informação, construir hipóteses e tomar decisões. Desta forma, o aluno conseguirá ir para além das informações dadas, atribuindo-lhes significado e apresentando-se como elemento ativo e construtor da sua própria aprendizagem e não um mero receptor de respostas corretas. $\mathrm{O}$ aluno vai construir novas ideias e conceitos baseados nos seus conhecimentos passados e atuais. (Ornelas, 2009, p.4)

A proposta metodológica de aprendizagem por descoberta, integra uma das propostas e pensamentos que consistem no embrião da Aprendizagem na Resolução de Problemas. Em sua essência, Bruner (2008) a defende como um método de ensino na qual há um confronto dos estudantes com problemas que os levarão a uma busca por uma solução. Para encontrar essa solução os estudantes deverão explorar suas experiências prévias e validar se precisam adquirir novos conhecimentos; essa necessidade será gerada pelas discussões em grupos. Esse sistema defende que os estudantes teriam mais facilidade para recordar o que foi estudado visto que durante o processo que se depararam com conflitos e controvérsias para chegar até a proposta de uma solução julgada como a mais pertinente para o contexto do problema. Bruner (2008) acredita que um indivíduo somente pode adquirir conhecimento a partir de um conhecimento prévio. Em suas palavras: [...]" destaca o processo da descoberta para ensinar por meio da exploração de alternativas. O ambiente ou conteúdo de ensino tem que ser percebido pelo aprendiz como uma série de problemas, e estes devem proporcionar alternativas" (Bruner ,2008, p.88).

Desta forma, a descoberta segundo Bruner (2008) pode ser compreendida como uma atividade de pesquisa, experimentação, investigação em que as crianças devem explorar as situações, de forma mais elaborada, na tentativa de encontrar soluções.

Dentre seus estudos e registros destaca-se a simpatia de Bruner com autores clássicos da Psicologia Educacional que influenciaram diretamente seus estudos. Dentre eles se destacam as ideias de Vygotsky - de interação e de diálogo no desenvolvimento e aprendizagem do ser humano; e Piaget - em suas ideias de desenvolvimento cognitivo em crianças, porém dava mais ênfase nas influências e desenvolvimento sociais (Costa, 2011; Harvard, 2012; Martins, 2002).

Bruner (1973c) nomeia sua teoria de Instrumentalismo Evolucionista, que em sua visão é definida como a dependência que o homem tem das técnicas para a realização da sua própria humanidade. Tornou-se conhecido pela seguinte frase: “É possível ensinar qualquer assunto, de uma maneira honesta, a qualquer criança em qualquer estágio de desenvolvimento". (Bruner, 1973c, p. 73,76). Essa expressão sinaliza que pode-se ensinar qualquer assunto, desde que se leve em conta as diversas etapas do

\footnotetext{
${ }^{3}$ Segundo Valsiner e Vasconcelos (1995) é uma corrente filosófica que surgiu com a obra de Piaget,no século XX, e desde então vem sendo apropriada por abordagens das mais diversas orientações ontológicas e epistemológicas. Considera o ser humano fruto de uma construção na qual interagem organismo e ambiente. No primeiro, estão presentes as condições genéticas; no segundo, a fonte dos estímulos que propiciarão o desenvolvimento. Defende que todas as pessoas nascem com o mesmo potencial de aprendizagem e que seu desenvolvimento posterior vai depender de sua história de vida, de seu meio cultural e social, do tipo de estímulo que recebe. É crer que não existem pessoas mais inteligentes do que outras e que a inteligência é uma conquista filogenética (da espécie) e ontogenética (de cada indivíduo), fruto de trabalho cognitivo mediado pela linguagem e conquistado no meio social.
} 
desenvolvimento intelectual em que a criança se encontra. Cada uma dessas etapas é caracterizada por um modo particular de representação, que é a forma pela qual o indivíduo visualiza o mundo e explica-o a si mesmo (Bruner, 1973c).

Baseado em Piaget, Bruner (1973c) usou a premissa de que a maturação e a interação do sujeito com o ambiente devem estar no centro do processo de desenvolvimento e de formação da pessoa; entretanto, coloca seu viés, ao dizer que "aquele que consiga incorporar a transmissão social, o processo de identificação e a imitação no processo de desenvolvimento e formação".

Estudiosos em Piaget defendem que essa tônica é dada devido a sua visão da capacidade de que cada pessoa tem de se conduzir associada a premissa de que o desenvolvimento cognitivo será tanto mais rápido quanto melhor for o acesso da pessoa a um meio cultural rico e estimulante. Sendo assim, para Bruner (1965 apud Souza, 2012, p.86) "a linguagem tem um papel amplificador das competências cognitivas da criança, ajudando-a a uma maior interação com o meio cultural".

Entretanto, não há somente discrepâncias entre as teorias de Bruner e Piaget. À semelhança de Piaget, Bruner separa as etapas do desenvolvimento cognitivo levando em consideração a maturidade do indivíduo enquanto que Piaget considera a maturidade e a idade de cada pessoa. Na concepção de Bruner há 3 fases do desenvolvimento: (1) observa-se as representações dos acontecimentos passados por meio de respostas motoras privilegiando os formatos de representação do real, por isso a criança nessa idade tem mais facilidade de aprender através da manipulação de objetos; (2) a representação icônica, baseia-se na organização visual, no uso de imagens sinópticas e na organização de percepções e imagens, reproduz objetos com grande facilidade, ela se faz bastante dependente de sua memória visual, concreta e específica; (3) a representação simbólica, constitui a forma mais elaborada de representação da realidade porque a criança começa a ser capaz de representar a realidade por meio de uma linguagem simbólica, de caráter abstrato e sem uma dependência direta da realidade por isso ela começa a ser capaz de manejar os símbolos ordenadamente e a transformar a realidade. A passagem por cada etapa pode se dar de forma mais acelerada ou não, dependendo da sua riqueza de imersão no meio cultural e linguístico (Marques, 2000, p.1-2).

$\mathrm{O}$ entendimento dessas fases fez com que as análises de Bruner o levassem a pensar na melhor forma para que os indivíduos aprendessem. Bruner (1965 apud SOUZA, 2012) em seus estudos também defendia que a criança tem quatro características que configuram seu gesto de aprender. A curiosidade, facilmente observável em qualquer criança, ele se arrisca a dizer que ela é uma característica que define a espécie humana. A procura de competência, também é observada em todas as crianças quando procuram imitar os adultos visando reproduzir e recriar seus comportamentos e suas competências. A reciprocidade, presente nos seres humanos, envolve a profunda necessidade de responder aos outros e de operar, junto com os outros, para alcançar objetivos comuns. E a narrativa, que é entendida como uma predisposição para a criação de relatos e narrativas de nossas próprias experiências, geralmente com a finalidade de transmitir essas experiências às demais pessoas. Ela também permite que essas mesmas experiências sejam compartilhadas, constituindo-se fundamentais no processo de aprendizagem. Com a narrativa torna-se possível a partilha de significados e de conceitos, de forma a alcançar modos de discurso que integrem as diferenças de significado e de interpretação (Marques, 2000, p.4).

Conforme a evolução das pesquisas e da maturidade de aplicação de sua teoria, Bruner (1965 apud Souza, 2012) passa a identificar padrões de comportamentos do crescimento cognitivo e do desenvolvimento de seus alunos que chamaram a sua atenção. Tais como: (1) os alunos desenvolvem a habilidade de responder às situações problemas apresentadas com pontos de vista diferentes, tentam encontrar formas variadas de encontrar a solução; (2) utilizavam-se da lógica do meio para responder às perguntas feitas, recorriam a conhecimentos e eventos prévios para formular uma hipótese, trabalhavam com mais variáveis que no início do processo; (3) os alunos em pouco tempo demonstravam melhor domínio da linguagem, se expressavam melhor, conseguiam defender seus pontos de vista, sem tanto receio de se expressar; (4) além de se comunicarem melhor entre eles e se expressarem melhor via-se reflexos desses avanços no contato com as demais pessoas, não somente aquelas relacionadas ao ambiente escolar, assim como outras figuras importante na vida das crianças;(5) Aos poucos nota-se que as crianças vão desenvolvendo habilidades de ordenação e de classificação do meio, do mundo em que vivem. Classificar o ambiente e ordená- 
lo torna-se uma tarefa cotidiana e automática para muitos. Isso influencia diretamente na sua forma de se relacionar com os desafios da vida, com as pessoas e com o meio; 6) Por fim, é notável a capacidade de as crianças lidarem com múltiplas tarefas e com situações que lhes demandam dinamicidade de pensamento e de ação.

Inicialmente os problemas demoram mais tempo para serem concluídos e solucionados, porém com o tempo e com todas as demais habilidades desenvolvidas os alunos aprendem a trabalhar em grupo, a se organizarem, e planejarem e a lidarem com mais de uma demanda ao mesmo tempo, fazendo assim, com que a mesma situação problema, mesmo que um pouco mais elaborada, seja trabalhada em menos tempo.

\section{A Teoria da Aprendizagem de Bruner no Ensino de Ciências Naturais}

O Ensino de Ciências é dinâmico e busca qualificação educacional, nesse contexto estabelece formas de melhorar o aprendizado dos alunos. Nesta ótica, a teoria de aprendizagem de Jerome Bruner pode ser tratada na área de Ciências Naturais, pois tem a concepção de que pode-se ensinar qualquer conteúdo ao indivíduo independente de sua idade, pois o que se considera é a maturidade cognitiva.

Jerome Bruner, de forma indireta, foi responsável pelo modelo de Ensino de Ciências Naturais implantado no país a partir da segunda metade do século XX, quando se refere à organização do currículo educacional brasileiro centrado na influência da Teoria de Instrumentalismo Evolucionista, termo criado por Bruner para descrever suas ideias no movimento reformista ocorrido no Brasil na década de 1960. Evidenciando assim, a análise das mudanças promovidas no currículo e nos materiais nacionais utilizados no Ensino de Ciências, principalmente na educação de nível superior e seus reflexos nos demais níveis de educação (Harry,2016).

Baseados nos princípios alinhados por Jerome Bruner, o Ensino de Ciências nas universidades brasileiras adotou uma nova conduta, ao inserir os novos materiais didáticos adequados a partir de materiais produzidos nos Estados Unidos e na Inglaterra, colocando o Brasil na vanguarda de um grupo seleto de países, como a Inglaterra, Argentina, Turquia, Itália, Japão, Austrália etc. (Maybury, 1975). As consequências da adoção, mesmo que de maneira não democrática, do modelo norteamericano, resultaram em inovações no desenvolvimento de materiais didáticos e na forma do Ensino de Ciências no Brasil.

Posteriormente, materiais didáticos que atendiam às necessidades das escolas brasileiras passaram a ser desenvolvidos, caracterizando, dessa forma, o movimento curricular de Ciências. A partir de 1972 com a instituição do Programa de Expansão e Melhoria do Ensino (PREMEN), foram organizados projetos apropriados ao ensino brasileiro, envolvendo educadores e cientistas brasileiros na elaboração de livros didáticos, guias para professores e recursos audiovisuais. Esses novos materiais produzidos evidenciam a visão de Bruner da natureza de uma disciplina científica como sendo um corpo organizado de conhecimentos, e um processo sistemático e criativo de adquirir esses conhecimentos.

Estudos apontam que apesar do investimento em materiais didáticos e o treinamento de professores para sua utilização, a melhoria na aprendizagem não foi a esperada. Problemas como a falta de laboratórios e equipamentos nas escolas, para a realização das atividades propostas, bem como o despreparo dos professores dificultaram a divulgação dos novos materiais. (Barra \& Lorenz, 1986)

Para compreender a importância de Bruner ao Ensino de Ciências, tem-se que analisar os seguintes pontos: o desenvolvimento intelectual, o ato da aprendizagem e a noção do currículo em espiral.

O ato da aprendizagem para Bruner (1973a) pode abranger os processos: (1) Aquisição, que se refere a obtenção de novas informações; (2)Transformação, que seria a manipulação do conhecimento a fim de adaptá-lo a novas tarefas; (3)Avaliação (crítica), forma de conferir se a maneira que manipulamos a informação é o mais adequado a determinada tarefa. A aprendizagem de um determinado assunto, normalmente envolve uma série de episódios. Para Bruner (1973a, p. 
45) um episódio de aprendizagem [...] "pode ser breve ou longo, conter muitas ou poucas ideias. A duração de um episódio depende das condições que cada aprendiz ou aluno pode sustentá-lo,conforme o que espera do seu esforço, no sentido de coisas exteriores, tais como notas ou graus ou também o que ganha em compreensão e conhecimento". Por isso, segundo Bruner (1773 a), os conteúdos devem ser adaptados conforme a necessidade e a capacidade dos alunos, respeitando suas especificidades.

\subsection{A Aprendizagem por Descoberta}

Para Goi e Santos (2018) Bruner distingue os “tipos de ensinar". Um deles está relacionado ao modelo expositivo e o outro ao modelo hipotético. O primeiro trata o professor como expositor e o estudante como ouvinte. O professor pode tomar decisões enquanto o aluno não tem discernimento das opções internas. No modelo hipotético, o professor e o estudante estão em uma posição de cooperação (Goi, 2014). Neste modelo, o estudante toma parte das formulações, fica ciente das alternativas e tem liberdade de expressão. Ainda segundo Goi e Santos (2018), para Bruner (2008), o modo hipotético caracteriza o ato de ensinar e isto leva ao encorajamento da descoberta. Aprender por meio de descobertas traz alguns benefícios como, a elevação do potencial intelectual; a passagem das recompensas extrínsecas para intrínsecas; o aprendizado da heurística do descobrimento e o auxílio da conservação da memória (Bruner, 2008).

Conforme Goi e Santos (2018), o processo de descoberta proposto por Jerome Bruner pode ser estimulado a partir da Resolução de Problemas em que o indivíduo, pesquisando e resolvendo determinadas situações, possa ampliar sua capacidade cognitiva e construir seu próprio conhecimento.

Pode-se ampliar essa importância também, para a Experimentação Investigativa, pois para Zanella (2019), uma atividade experimental elaborada de forma a colocar o estudante diante de uma situação problema, que tenha relação com seu cotidiano, permitirá que ele possa raciocinar logicamente sobre a situação, questionando seus conhecimentos prévios, que o levarão a interpretar as etapas da investigação, elaborando hipóteses, através da análise de dados, apresentando argumentos, que o conduzirão a uma conclusão plausível. Alcançando os objetivos de uma atividade experimental, a qual privilegia o desenvolvimento de habilidades cognitivas e o raciocínio lógico apontados por Bruner.

O método da descoberta tem sido questionado, pois a aprendizagem pelo mesmo pode-se dar de forma mecânica, ou seja, o estudante só consegue alcançar aquele resultado por meio do caminho proposto pelo professor, memorizando passos sem que proponha alternativas para uma nova solução à situação problema. O próprio Bruner, anos após a publicação de seus livros sobre sua teoria de aprendizagem, revisa algumas questões e propõe a adaptação no ensino em favor de contextualizá-las aos problemas que a sociedade enfrenta. A ideia de que a experimentação levaria à compreensão ou até mesmo à redescoberta de leis científicas não pode ser exclusividade em um projeto. Para o pesquisador "um bom intuitivo pode ter nascido com algo especial, mas a sua intuição funciona melhor quando ele tem um sólido conhecimento do conteúdo, uma familiaridade que dá substância à intuição" (Bruner, 1973a, p.56).

Contudo, sabe-se que o pensamento de Bruner foi fundamental para a ressignificação do Ensino de Ciências e para a evolução dos processos de ensino e de aprendizagem. A perspectiva de uma aprendizagem por descoberta pode ser o gatilho para despertar a curiosidade dos jovens, atitude necessária ao desenvolvimento de outras habilidades, sendo, portanto, importante para o Ensino de Ciências.

\subsection{Concepções sobre o Currículo em Espiral}

Segundo Roldão (1994), o Currículo em Espiral de Bruner é fundamentado pela caracterização do desenvolvimento dos estágios ou fases. No entanto, esta fundamentação é vista como uma orientação para adaptar estratégias de ensino aos diferentes modos de ver e representar o mundo em diferentes idades e não para selecionar ou excluir conteúdos ou conceitos. 
Bruner, apesar de ter estabelecido uma sequência de fases, se preocupa mais com a especificidade qualitativa da compreensão das crianças em cada fase. Decorrente da preferência pelo método da descoberta e da teoria da aprendizagem em espiral, surge a proposta de organização dos currículos e das práticas de ensino em torno do processo de reconstrução dos saberes científicos, através “da interiorização dos seus princípios e da tentativa de aplicação dos seus métodos”. (Roldão, 1994, p. 64)

Portanto, o Currículo em Espiral defendido por Bruner (1969) é um método de ensino que consiste na apresentação de conceitos básicos que são ensinados em um primeiro momento e depois revistos em diferentes níveis de profundidade, complexidade e formas de representação. Nessa concepção de currículo, o ensino não se caracterizaria por sua abrangência, mas por sua profundidade colocando em evidência o maior número de particularidades possíveis. Assim, este modelo de currículo deveria iniciar com uma descrição intuitiva de uma área do conhecimento, circulando de volta para representar essa área de modo mais formal.

Segundo Bruner (1973a), para alcançar o estado de um adulto estabelecido cognitivamente, deve-se fazer uma transposição do conteúdo a ser ensinado para as suas formas de pensar e refletir, considerando as características do desenvolvimento intelectual do indivíduo e desafiando-o progressivamente.

Temas, princípios e valores, que sejam de relevância para a sociedade, devem fazer parte do currículo escolar além de serem trabalhados de forma contínua e não esporádica (Bruner,1973a).

Segundo Silva e Gomes (2017) quando se pressupõe que é necessário a compreensão de números, medida ou probabilidade na compreensão da ciência, mais cedo possível, de uma maneira intelectualmente mais "honesta", levando a forma de pensar da criança, esses tópicos deverão ser apresentados progressivamente, contribuindo dessa forma para o progresso do desenvolvimento do conhecimento.

Figura 1: Esquema do Currículo em Espiral.

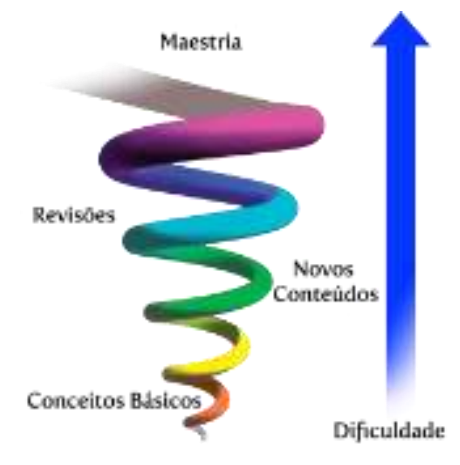

Fonte: Sargiani (2016).

O Currículo em Espiral, conforme a Figura 1, consiste em um método de ensino que apresenta os conceitos básicos em um primeiro momento e depois revistos em diferentes anos, sempre aumentando o nível de profundidade, complexidade e modos de representação. Assim, as crianças aprendem o básico sobre um assunto, e depois passam a revisitar esse conteúdo e incorporar outros conhecimentos mais complexos sobre o mesmo fenômeno, como em uma espiral.

Para Rabatini (2010), o conceito de aprendizagem em espiral pode enunciar-se da seguinte forma:

Qualquer Ciência pode ser ensinada, pelo menos nas suas formas mais simples, a estudantes de todas as idades, uma vez que os mesmos tópicos serão, posteriormente, retomados e aprofundados mais tarde. Sendo assim, um dos principais benefícios dessa aprendizagem é o fato de ser uma metodologia ativa de aprendizagem, pois, permite ao aprendiz sua participação durante o ensino, despertando sua curiosidade a explorar diferentes alternativas. Além de permitir a oportunidade de ver o mesmo tópico mais de uma vez com diferentes níveis de profundidade e diferentes formas de representação. (Rabatini, 2010, p.43-44) 
Assim, as bases essenciais de qualquer disciplina científica podem ser ensinadas aos estudantes em qualquer idade de forma fidedigna.

Segundo Rabatini (2010), para Bruner, os meios para se ajudar um aprendiz é chamado de currículo, e não o que se aprende, já que currículo seria uma conversa "animada" com apoios, figuras, textos, filmes e demonstrações. Esse processo incluiria a conversa, mais exposição ou demonstração, meditação e cada um realizando isto por si mesmo.

Segundo Bruner (2001, p.9) [...] “o professor, nesta versão de pedagogia, é um guia para o entendimento, alguém que ajuda o aluno a descobrir por conta própria”, na verdade um tipo de capacitor. Para o autor:

Os encontros educacionais, em princípio, deveriam resultar em entendimento, não em simples desempenho. O entendimento consiste na compreensão de uma ideia ou de um fato em uma estrutura mais geral de conhecimento. Quando entendemos algo, o entendemos como um exemplar de um princípio conceitual ou teoria mais ampla. O conhecimento em si, além disso, é organizado de tal maneira que a apreensão de sua estrutura conceitual torna seus pormenores mais evidentes, até mesmo redundantes. Além disso, o conhecimento adquirido é mais útil para alguém que está aprendendo quando ele é “descoberto" por meio dos esforços cognitivos do próprio indivíduo que está aprendendo, pois, dessa forma, ele é relacionado ao que se conhecia antes e utilizado em referência a isto. Tais atos de descoberta são enormemente facilitados pela estrutura do próprio conhecimento, pois não importa quão complicada seja uma área de conhecimento, a mesma pode ser representada por formas que a tornam acessível por meio de processos menos complexos e elaborados. Foi essa a conclusão que me levou a propor que qualquer matéria poderia ser ensinada a qualquer criança em qualquer idade de uma forma honesta - embora honesta tenha ficado sem uma definição e tenha me perseguido desde então! (Bruner, 2001, p. 9).

Para tanto, o Currículo em Espiral propõe a ideia de que ao se ensinar fenômenos químicos e físicos por exemplo, em uma aula de Ciências, deve-se começar o assunto de maneira informal e que esteja ao alcance do aluno e, posteriormente, abordar de maneira mais formal, de acordo com a evolução do aprendiz. Isso se dá quantas vezes forem necessárias, até que o aluno tenha dominado o assunto ou matéria em seu poder generativo pleno.

O Currículo em Espiral, além de favorecer o aumento do desempenho escolar, também contribui para que os estudantes criem o hábito de estudar, já que são incentivados a identificarem problemas, elaborarem perguntas, formularem explicações e construírem novos significados.

\section{Considerações Finais}

Neste artigo buscou-se destacar a teoria de Bruner, uma vez que desde meados do século passado está sendo estudada por pesquisadores cognitivistas, porém ainda há um predomínio de teorias behavioristas e estas ainda vem sendo implementadas nos contextos escolares.

Sabendo dos momentos de crise em que passa o ensino tradicional, sendo tachado de fracassado e retrógrado, pois suas concepções não acompanham e representam mais os objetivos e anseios de nossa sociedade.Tais anseios são abordados em reuniões pedagógicas da Educação Básica, mas muito pouco tem sido feito para mudar esse panorama, devido ao desestímulo por parte dos professores aliadas às políticas públicas vigentes na Educação.

Por isso busca-se estimular mudanças com implementações e estudos de teorias de aprendizagem, visto que o objetivo da Educação é ter estudantes que possam compreender os conteúdos e não somente decorá-los, mas relacioná-los com as mais diversas situações e problemas que possam ser resolvidos e que tenham significado. Desse modo almeja-se pessoas que pensem, critiquem, que sejam cidadãos ativos e participativos no contexto social em que está inserido.

Reconhece-se que a teoria de Bruner está pautada na participação ativa do estudante para o desenvolvimento do seu processo de aprendizagem por meio da descoberta, a exploração de novas alternativas, o Currículo em Espiral e a aprendizagem segundo as fases internas do desenvolvimento. Ao adotar esta ideia, Bruner reconhece que a criança nem sempre é capaz de construir por si só, mas depende de uma direção dada por seu educador. Aquilo que é construído em sua 
consciência é o que foi aceito interpessoalmente; somente aquilo a que a criança pode assegurar "concordância compartilhada" torna-se parte de sua representação do mundo.

Nessa perspectiva, pode-se dizer que a teoria de Bruner contribui para o Ensino de Ciências quando o estudante assume um papel central no processo de aprendizagem. Assim, cabe-lhe a construção de seu conhecimento através da heurística da descoberta, da investigação, bem como da Resolução de Problemas, construindo e desconstruindo significados pessoais. Também proporciona um Ensino de Ciências que leva em consideração o processo de se fazer a Ciência, ao contrário da mera exposição de uma Ciência pronta, propondo um ensino voltado para a sensibilidade metacognitiva levando o estudante ao alcance da compreensão do conhecimento científico.

\section{Referências}

Amil, A. B. (S/D.) Jerome Bruner. 〈http://psicologia.historiapsi.com/wp-content/uploads/2012/06/Brunerbiograf\%C3\%ADa.pdf〉.

Ausubel, D., Novak, J. D., \& Hanesian, H. Psicologia Educacional. (2a ed.) Editora Interamericana, RJ. Ano: 1980.

Barra, V., \& Lorentz, K. M. (1986) Produção de material didático de ciências no Brasil, período de 1950 a 1980. Ciência e Cultura, $38(12)$, $1971-1983$.

Bruner, J. S. (1973a) O Processo da Educação. (5a ed.) Nacional, 87 p.

Bruner, J. S. (1973c) Uma Nova Teoria de Aprendizagem. (2a ed.) Bloch, 162 p.

Bruner, J. S.(2001) A Cultura da Educação. Artes Médicas, [Publicado originalmente em 1996]

Bruner, J. S. (2008). Sobre o Conhecimento: Ensaios de mãos esquerda. Phorte

Bruner, J. S., Goodnow, J. J., \& Austin, G. A. [1956] (2017). A study of thinking. Routledge.

Cervo, A. L. \& Bervian, P. A. (2002) Metodologia científica. (5a ed.) Prentice Hall.

Costa, C. R. C. M., \& Maia, H. (2011) Ações executivas. In Dias, A. P. B., Maia, H.(orgs) Neurociência e Desenvolvimento Cognitivo. 19-30.

Goi, M. E. J., \& Santos,F. M. T.(2018) Contribuições de Jerome Bruner: aspectos psicológicos relacionados à resolução de problemas na formação de professores de ciências da natureza. Ciência e Cognição. 23(2), 315-332.

Harry, J. O. (2016) Contribuição Bruneriana para o Ensino de Ciências. Saberes Docentes em Ação. 2(1). http://www.maceio.al.gov.br/wpcontent/uploads/lucasragucci/pdf/2016/11/20-CONTRIBUI\%C3\%87\%C3\%83O-BRUNERIANA.pdf,

Harvard University (2020, July 05). Learning Theories: Discovery Learning (Bruner). Disponível em:https://www.learning-theories.com/discovery-learningbruner.html .

Kuhn, T. S. (1998) A Estrutura das Revoluções Científicas. Editora Perspectiva. (5a ed.)

Martins, J. G. (2002) Aprendizagem Baseada em Problemas aplicada ao ambiente virtual de aprendizagem. 219 f. Tese (Doutorado) - Curso de Engenharia da Produção, Universidade Federal de Santa Catarina, Florianópolis.

Moreira, M. A. (1999) Teorias de Aprendizagem. Editora Pedagógica e Universitária.

Maybury, R. H. (1975) Technical assistance and innovation in Science education. John Wiley \& Sons.

Ornelas, M. (2009) Motivar e ensinar através da experimentação. Lisboa. https://www.academia.edu/2339529/Motivar_e_ensinar_atrav\%C3\%A9 s_da_experimenta\%C3\%A7\%C3\%A3o

Piaget, J. (2008) Psicologia e Pedagogia. (9a ed.) Forense Universitária. 184p.

Rabatini, V. G. (2010) A concepção de cultura em bruner e vigotski:: implicações para a educação escolar. Dissertação de Mestrado, apresentada ao Programa de Pós-Graduação em Educação Escolar da Faculdade de Ciências e Letras - UNESP/ARARAQUARA. http://wwws.fclar.unesp.br/agendapos/educacao_escolar/2125.pdf

Roldão, M. C. (1994). O Pensamento Concreto da Criança: Uma Perspectiva a Questionar no Currículo. IIE

Sargiani, R. (2016). Histórias e Biografias: Jerome Bruner. Psicologia Explica. https://www.psicologiaexplica.com.br/jerome-bruner/

Silva, A. H. (2017) A teoria de aprendizagem de Bruner e o ensino de ciências. Arquivos do MUDI, 21(3), 13-24. file://C:/Documents\%20and\%20Settings/Administrador/Meus\%20documentos/Downloads/40938-Texto\%20do\%20artigo-180240-1-10-20171212\%20(2).pdf.

Souza, F. S. U. (2012) Aprendizagem baseada em problema: seria essa uma metodologia de ensino possível de ser aplicada ao ensino fundamental I? Trabalho de Conclusão de Curso apresentado como exigência parcial para a conclusão do curso de Pedagogia pela Faculdade de Educação da Unicamp.Campinas. http://www.bibliotecadigital.unicamp.br/document/?view=000897611. 
Research, Society and Development, v. 10, n. 13, e367101321214, 2021

(CC BY 4.0) | ISSN 2525-3409 | DOI: http://dx.doi.org/10.33448/rsd-v10i13.21214

Valsiner, J. Vasconcelos, V. M. de.(1995) Perspectiva Co-Construtivista na Psicologia e na Educação. Artes Médicas.

Zanella, J. I. (2019) Análise da construção de conhecimento teórico e prático: elaboração de atividades experimentais investigativas. Dissertação de Mestrado apresentado ao programa de Mestrado Profissional em Química em Rede Nacional, da UFRGS. www.lume.ufrgs.br/bitstream/handle/ 10183/204546/001109435.pdf?sequence=1. 